\title{
Avaliação da segurança na utilização de aparelhos de musculação por idosos
}

Safety evaluation in the use of fitness equipment by the elderly

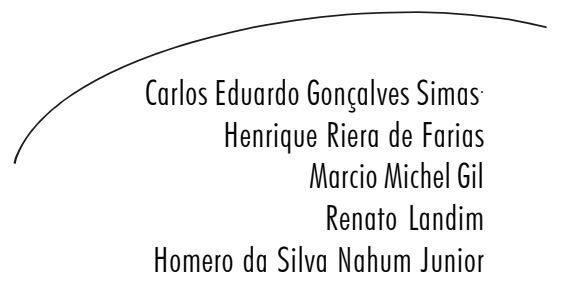

\section{Resumo}

O estudo teve como objetivo avaliar a segurança na utilização de aparelhos de musculação por indivíduos idosos, e para tanto foram entrevistados 90 voluntários, sendo 64 mulheres $(71,11 \%)$ e 26 homens. $(28,89 \%)$. Os dados foram coletados por meio de questionário cujas respostas foram tratadas pela análise de freqüência e posteriormente comparadas pelo teste Quiquadrado $(a ́=0,05)$. Foi possível concluir que a prática da musculação se deu com objetivo de saúde $(60,83 \%)$, sendo a hidroginástica a outra modalidade de interesse do grupo $(80,00 \%)$. Declararam ter alguma dificuldade nos aparelhos 54,44\% dos voluntários,, particularmente esteira, leg press, cadeira extensora, supino ou pulley. Apesar disso, $87,78 \%$ dos idosos declararam se sentir seguros ou plenamente seguros nos aparelhos, não havendo, para a maioria, necessidade de auxílio humano ou de objeto para entrada, execução ou saída de qualquer aparelho. Dentre os problemas de saúde mais ocorrentes, os articulares e diversos (cardiovascular, respiratório e diabetes), com respectivamente $34,86 \%$ e $38,53 \%$, apresentaram as maiores freqüências. Os resultados não guardaram correspondência com os comportamentos observados, refletindo talvez a relação de afetividade professor-aluno, a qual definiu respostas que "protegessem" o profissional de Educação Física.

\author{
Palavras-chave: \\ estudos de \\ avaliação; seguran- \\ ça de equipamen- \\ tos; equipamentos \\ e provisões / \\ utilização; ativida- \\ de motora ; idoso
}

\footnotetext{
Universidade Estácio de Sá

Curso de Educação Física

Rio de Janeiro, RJ, Brasil

Correspondência / Correspondence

Renato Landim

E-mail: landimtupi@yahoo.com.br
} 
Abstract

This study aimed to evaluate the safety of elders during the use of fitness equipment. Ninety subjects were interviewed, 64 women $(71.11 \%)$ and 26 men $(28.89 \%)$. Data were collected through a questionnaire. Answers were treated with frequency analysis and then compared by Qui-squared test (a $=0.05)$, allowing to conclude that fitness practice's primary goal was to improve health conditions $(60.83 \%)$, and hydro-gymnastics was the second activity that most interested subjects (80.00\%). Among the subjects, $54.44 \%$ reported some difficulty to use equipments, particularly treadmill, leg press, extensor chair, machine chest press and pulley. Despite that, subjects were familiarized with equipments, and $87.78 \%$ of them declared feeling safe or completely safe using the machines and expressing no need for human help or any object support during the entry, execution or exit of all machines. Among the most recurrent health conditions, articulation conditions and diverse (cardiovascular, respiratory and diabetes) showed the highest frequency $(34.86 \%$ and $38.53 \%$, respectively). Results did not keep correspondence with the observed behavior, and this bias may express the personal teacher-student relation, defining answers that protected the physical education professor.

\section{INTRODUÇÃO}

A população de idosos vem crescendo de forma significativa no país e, paralelamente, ${ }^{1}$ há a preocupação em se manter este grupo cada vez mais ativo, através de atividades ou exercícios físicos. O objetivo é mantê-lo cada vez mais independente, útil e se beneficiando de vários componentes, como saúde, sociabilização, interação, auto-estima, autoconfiança, auto-imagem, flexibilidade, resistência aeróbia, de força e massa musculares, motilidade gastro-intestinal, melhora dos fatores neurais, diminuição de lesão causada por queda e prevenção de doenças como obesidade, hipertensão, diabetes, osteoporose, doenças cardiorrespiratórias, artrite, artrose e depressão.,
Key words: evaluation studies; equipment safety; equipment and supplies /utilization; motor activity; aged
A deficiência muscular é hoje uma das maiores causas da incapacidade funcional, limitando atividades diárias, como subir escadas, manter sua postura músculoesquelética, levantar de um assento, carregar sacolas de compras e outras. ${ }^{2}$

Há 16 anos ficou comprovado que os idosos podem se beneficiar da participação em exercícios contra resistência, devido à perda de massa muscular que ocorre com o avanço da idade e à necessidade de compensá-la com o aumento da capacidade de gerar força. ${ }^{3}$ Segundo Campos, ${ }^{2}$ o sujeito começa a desenvolver sarcopenia em torno dos 28 anos, de forma gradativa, e após os 60 anos, muito mais intensamente, devido às alterações fisiológicas, como redução de massa magra e óssea, favore- 
cendo assim a diminuição da massa e potência musculares.

Não se pode deixar de priorizar a segurança para todas as atividades que têm como objetivo a saúde e a qualidade de vida, isto é, envelhecer de maneira saudável, com reconhecimento, respeito e segurança. ${ }^{1}$

Cabe ressaltar que os idosos apresentam dificuldades na utilização de alguns aparelhos no ambiente de treinamento de força, o que exige o desenvolvimento de meios e a atenção focada na preservação da integridade física deste grupo, tendo em vista as dificuldades percebidas e a iminência de acidentes.

Segundo Dantas e Oliveira, ${ }^{4}$ o envelhecimento é o declínio das funções fisiológicas que ocorrem de forma progressiva, acometendo a capacidade funcional. É possivelmente uma causa de insegurança ao locomover-se, mas esse processo não deve ser tomado como doença, e sim como na- tural. Sua velocidade varia de forma bastante individual e pode ser evidenciada por causas diversas como, por exemplo, a codificação genotípica.

O processo de envelhecimento se manifesta diferentemente e as alterações obedecem a um regime estocástico, em função do indivíduo. Fatores diversos, como doenças, estresse emocional e meio ambiente vão determinar a rapidez desse processo. ${ }^{1}$

Em Nóbrega et al., ${ }^{5}$ o envelhecimento é um processo que gradativamente conduz o sujeito à inatividade física, que por sua vez leva ao descondicionamento e à potencialização da fragilidade músculoesquelética. Com o acúmulo dessas variáveis, ocorre a perda do estilo de vida independente, ocasionando diminuição da motivação e auto-estima, havendo possibilidade de atingir um grau de ansiedade e depressão, que neste caso aceleraria a inatividade física e o envelhecimento (figura 1). ${ }^{6}$

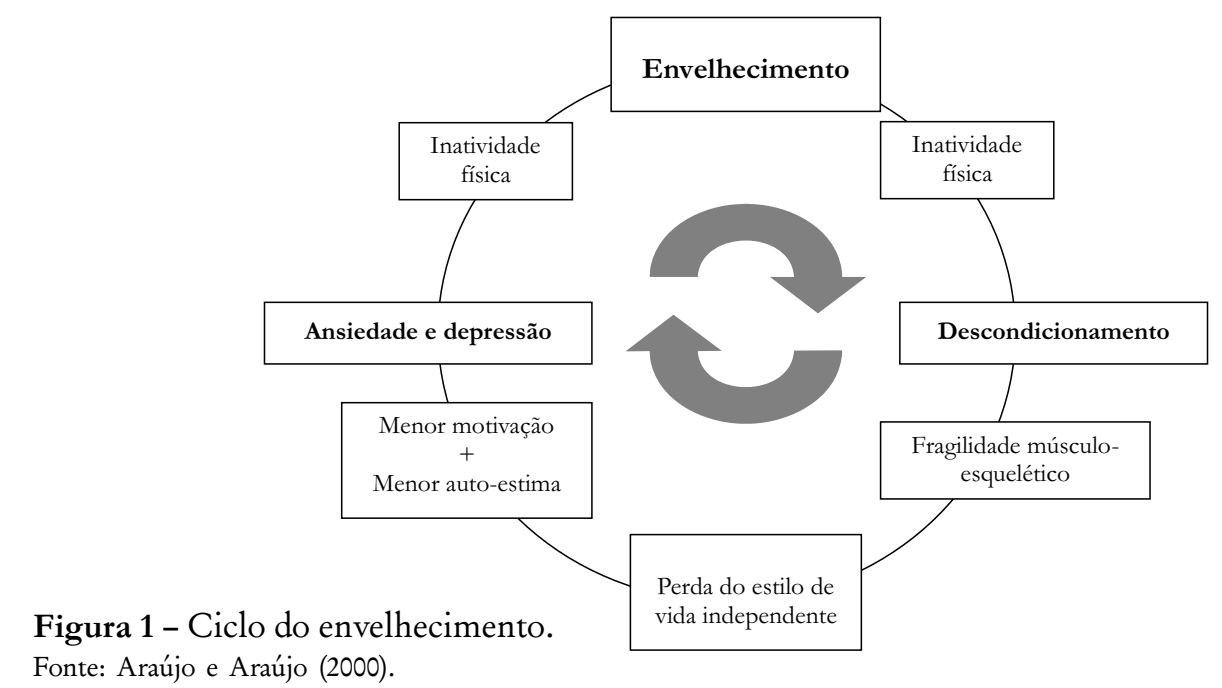


Os órgãos diminuem gradativamente suas capacidades funcionais e, como conseqüência, todos os sistemas serão afetados, impedindo o idoso de realizar as tarefas mais simples do cotidiano, como o ato de caminhar. Esse processo tem características nas reduções das funções dos sistemas orgânicos. ${ }^{1,6,7} \mathrm{Em}$ função disto, o presente trabalho objetivou avaliar a segurança na utilização de aparelhos de musculação por indivíduos idosos.

\section{MATERIAIS E METODOS}

O estudo foi realizado com 90 idosos voluntários, sendo 26 homens e 64 mulheres, em academias nos bairros do Maracanã, Engenho de Dentro, Copacabana, Tijuca, Flamengo e Laranjeiras, situados no Município do Rio de Janeiro.

A coleta de dados ocorreu através da aplicação de um questionário contendo 13 questões, sendo uma aberta. Esse instrumento foi aplicado como entrevista realizada de forma individual, com praticantes de musculação acima de 60 anos, no local onde praticam sua atividade física, até mesmo durante a prática. Os participantes assinaram o termo de consentimento livre e informado, que esclarecia sobre o processo e objetivo da pesquisa, obedecendo à essência conceitual apresentada por Nahum Junior et al..$^{8}$ Os referidos autores demonstraram que somente é imperativo que haja validação de instrumentos subjetivos quando estes forem classificados como formulários, os quais podem levar a interpretações distintas sobre as perguntas.
Soma-se a isto a possibilidade de elevação da variabilidade de respostas, em virtude de erros de preenchimento ou ausência de resposta na utilização de formulários, ${ }^{9}$ aspectos inerentes à impossibilidade de verificação da veracidade das respostas. Tais considerações, excetuando-se a última, não se fizeram presentes neste trabalho, em virtude da adoção do questionário em detrimento do formulário.

Foram entrevistados 120 idosos, porém somente 90 responderam a todas as questões levantadas. Por isso, os 30 que não responderam como esperado, não foram incluídos na amostra. Outro fator de inclusão foi a idade acima de 60 anos e a prática de musculação.

No primeiro momento, os dados foram tratados através da análise descritiva. ${ }^{10}$ Desta forma, para a variável idade foram estimadas média, mediana, desvio-padrão, coeficiente de variação e erro-padrão, visando a caracterizar o grupo em função da citada variável contínua. As demais variáveis eram qualitativas, portanto a abordagem empregada foi a análise de freqüência, a qual permitiu representar resultados através de tabelas ou gráficos de freqüência. ${ }^{11}$ Visando à verificação da significância das ocorrências no domínio qualitativo foi empregado o Teste Qui-quadrado, ${ }^{12}$ tendo $\propto=0,05$ e:

HO: As freqüências da variável $i$ eram uniformes;

H1: Pelo menos uma freqüência da variável $i$ era distinta das demais. 
$\forall i \in \mathrm{I}=\{$ sexo, objetivo, outra atividade, insegurança, auxílio humano entrada, auxílio humano execução, auxílio humano saí$\mathrm{da}$, auxilio objeto entrada, auxilio objeto execução, auxilio objeto saída, dificuldade, problema saúde\}.

\section{DISCUSSÃO DE RESULTADOS}

Cabe ressaltar que os aparelhos foram previamente selecionados para o grupo, tendo em vista que inicialmente o professor percebeu que a turma sentia dificuldade na utilização de alguns aparelhos, como mesa flexora e cadeira extensora. Assim, as séries são baseadas neste fato e apesar de se esclarecer o objetivo do questionário antes $\mathrm{da}$ entrevista, supõe-se que os idosos não assumiram completamente suas dificuldades e inseguranças. A maioria não admitiu insegurança ou dificuldade, apesar de algumas contradições durante as entrevistas, como por exemplo, uma senhora caminhava na esteira durante a entrevista, apoiando as duas mãos no aparelho, respondeu que se sentia segura em todos os aparelhos, mas quando foi perguntada se era capaz de caminhar sem o tal apoio, auxilio de algum objeto, admitiu que não se sentia segura suficiente e que provavelmente sofreria uma queda.

Apesar de os professores de musculação contribuírem no sentido de esclarecer o objetivo da entrevista para as turmas, a maioria dos idosos não colaborou com a pesquisa. A população entrevistada demonstrou cuidado e receio com as respostas, deixan- do transparecer a proteção do profissional da área de musculação, embora não exista relação da resposta e comprometimento da atuação do professor.

Observou-se que parte do grupo das academias dos bairros do Flamengo e Copacabana freqüentou inicialmente a sala de musculação para pessoas de faixas etárias variadas. Após perceberem algumas dificuldades e insegurança dos professores, esses idosos foram encaminhados para uma sala menor e passaram a realizar séries de acordo com as dificuldades apresentadas, mais bem controladas pelos profissionais.

Especificamente no que se refere aos resultados, o grupo apresentou elevada variabilidade (coeficiente de variação $\geq 20,00 \%$ ), caracterizada pela mediana $(70,00$ anos \pm $100,21 \%)$. Logo os voluntários perfizeram um grupo não-uniforme (tabela 1), que levaria a respostas distintas devido à história de vida de cada um, experiências, influência do meio e condições socioculturais. Tal fato convergiu com a expectativa dos autores, pois não houve limitação de idade no escopo do trabalho. Como conseqüência, é provável que a idade característica tenha influenciado as demais respostas - logo, a priori as variáveis subseqüentes deviam demonstrar a alta variabilidade. Os resultados guardaram correspondência com os estudos de Bondim, ${ }^{13}$ que investigou os fatores que motivavam pessoas acima de 60 anos à prática de exercícios físicos em academia de ginástica; e Lima, ${ }^{14}$ que discutiu o envelhecimento sob a ótica educacional. 
Tabela 1 - Resultados descritivos da variável idade, Rio de Janeiro, RJ, 2007.

\begin{tabular}{lc}
\hline \multicolumn{1}{c}{ Estatística } & Estimativa \\
\hline Média & 69,86 \\
Desvio-padrão & 6,28 \\
Mediana & 70,00 \\
Coeficiente de Variação (\%) & 100,21 \\
Erro-padrão & 0,66 \\
\hline
\end{tabular}

No tocante à variável sexo (figura 2), percebeu-se predominância do público feminino $(71,11 \%)$, talvez devido à maior expectativa de vida, ao fato de população feminina ser maior que a masculina, à questão da vaidade e à preocupação com saúde. ${ }^{15} \mathrm{Va}$ liño, Teixeira e Vasconcelos, ${ }^{16}$ ao investigarem os hábitos de vida de idosos praticantes e não-praticantes de atividade física em academia, também demonstraram predominância do público feminino. Convergência semelhante se deu com Nascimento, ${ }^{17}$ que estudou a autonomia funcional de idosos sedentários e praticantes de musculação, ginástica localizada e hidroginástica.

Segundo Souza et al., ${ }^{18}$ em estudo sobre qualidade de vida e bem-estar de ido- sos portugueses do ponto de vista dos próprios, houve uma resposta bastante positiva, sendo que a minoria apresentou problemas de diminuição cognitiva grave ou algum grau de dependência, segundo boas qualidades psicométricas analisadas a partir do Easy care. Foram encontrados quatro fatores representativos dessa análise: atividades da vida diária, bem-estar, mobilidade e comunicação. Para os autores, isso explica mesmo que parcialmente a superioridade numérica do público feminino idoso, $59,10 \%$ da população portuguesa. O comportamento observado no presente estudo revelou concordância, quando se verificou percentual de mulheres maior do que o de homens, indicando longevidade maior das mulheres.

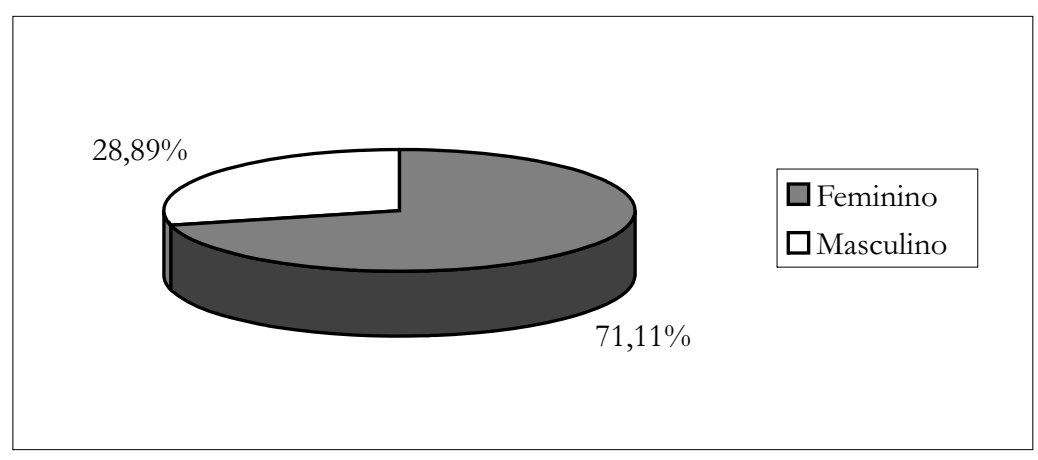

Figura 2 - Freqüência da variável Sexo, Rio de Janeiro, RJ, 2007. 
A maioria dos idosos praticava musculação tendo como principal objetivo a saúde $(60,83 \%)$, atendendo às expectativas como resultado final, com exceção da posição da sociabilização $(6,67 \%)$, pois é senso comum o discurso associativo entre atividade física e saúde (figura 3). Bondim ${ }^{13}$ observou uma procura pela atividade em academia, motivada, sobretudo por vontade própria, não se sabendo exatamente o ob- jetivo; em segundo lugar vem a indicação médica, buscando-se a saúde como objetivo. Por fim, nenhum deles foi indicado por amigos, o que pode caracterizar uma baixa sociabilização. Percebeu-se então um paralelo com este trabalho, na qual a procura pela atividade motivada pela busca da saúde ou sua manutenção aparece em primeiro lugar, enquanto a sociabilização como objetivo principal teve baixa quantificação.

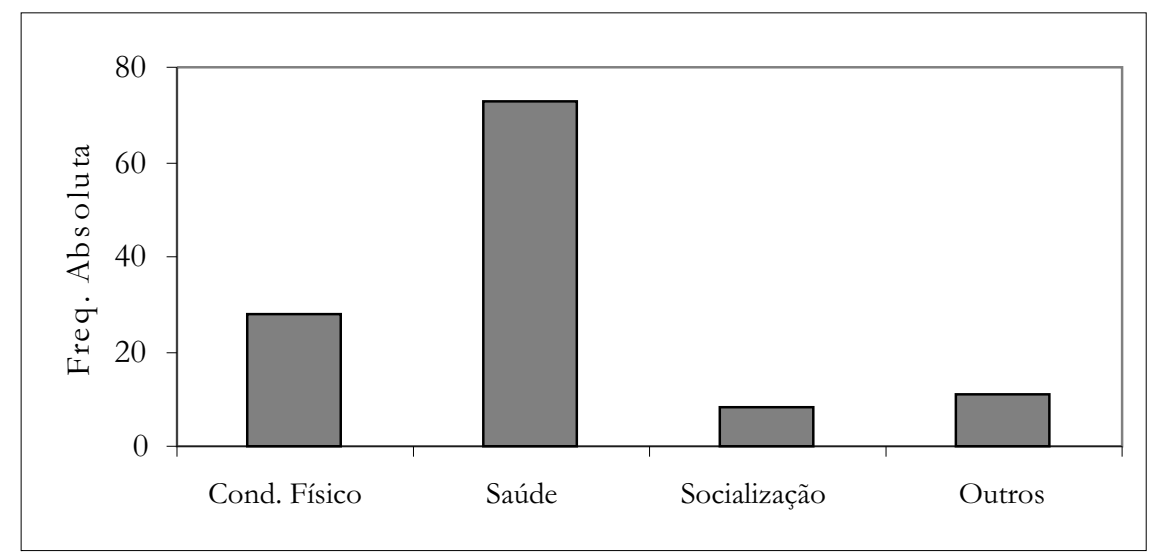

Figura 3 - Freqüência da variável Objetivo, Rio de Janeiro, RJ, 2007.

Cerca de $80,00 \%$ do grupo fazia outra atividade física, e a figura 4 demonstrou que o grupo estava sendo aparentemente bem orientado, tendo em vista a coerência dos resultados com a variável anterior. Ou seja, objetivos de saúde e condicionamento físico exigem estímulos variados, os quais, a julgar pela diversidade de opções, deveriam estar presentes na prática daqueles idosos. As atividades de baixo impacto podem contribuir de fato para o equilíbrio, força, concentração e melhora do sistema cardiorrespiratório, favorecendo assim o melhor de- sempenho nas tarefas diárias com menor risco de queda e lesão.

Conforme verificado por Nascimento, ${ }^{17}$ a hidroginástica aparece como a atividade mais procurada, juntamente com a musculação, apresentando eficiência na melhora da mobilidade articular e conseqüente independência no ato de movimentar-se. Assim, a prática de outra modalidade pode favorecer o desenvolvimento do vocabulário motor, e a priori contribui para a elevação da sensação de segurança. 


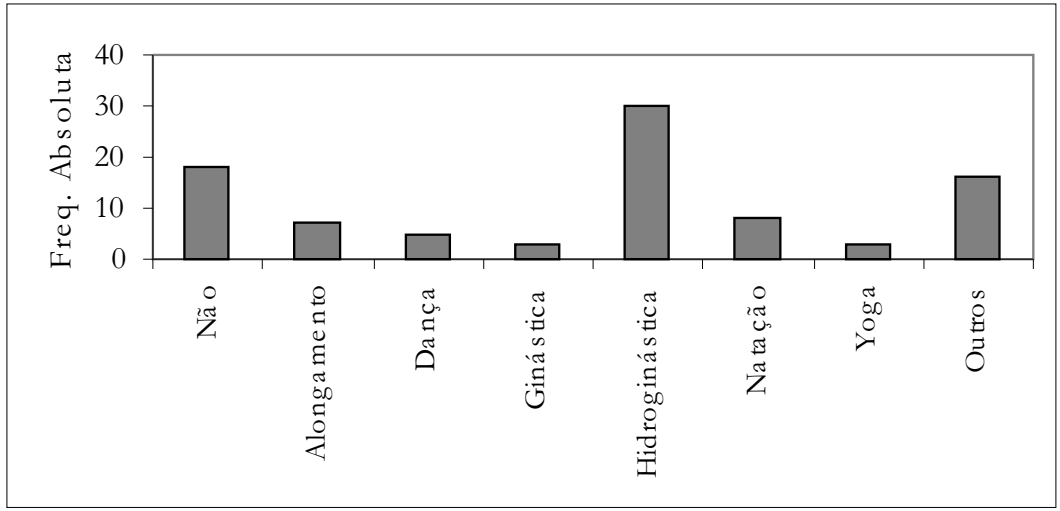

Figura 4 - Freqüência da variável Outra Atividade, Rio de Janeiro, RJ, 2007.

Quarenta e nove participantes (54,44\%) declaram dificuldade na utilização de algum aparelho (tabela 2), estando as mesmas ocorrências concentradas em esteira $(18,37 \%$ dos respondentes), leg press $(14,28 \%)$, cadeira extensora $(10,20 \%)$, supino $(10,20 \%)$ e pulley $(8,16 \%)$. Esse fato pode indicar a existência de comprometimentos na capacidade locomotora dos voluntários e, conseqüentemente, o desenvolvimento de dificuldades na execução de movimentos relacionados ao cotidiano.

A análise da lista de aparelhos conduz a análise à utilização de grandes grupos musculares e exercícios multiarticulares, aspecto que pode comprovar a maior complexidade na execução dos movimentos - logo se ratifica a possibilidade de existência de algum grau de insegurança.

A presunção anterior não se confirmou, pois as opções "segurança" e "plena segurança" detiveram $87,78 \%$ das ocorrências no questionamento sobre a percepção de inse- gurança (figura 5). Assim, pode ter ocorrido o mascaramento da realidade, ocasionado por relações de afetividade entre alunos e professor, pois percepções anteriores, que motivaram a realização do presente estudo, indicavam níveis de insegurança na execução de exercícios.

Os resultados anteriores foram coerentes com elevados níveis de independência, superando a expectativa para a idade, particularmente quando se considera a predominância de saúde como objetivo, o qual a princípio indicaria que o grupo deteria significativas perdas óssea e muscular, tal qual discutido por Rocas. ${ }^{19} \mathrm{Se}$ assim o fosse, então os idosos deveriam necessitar de auxílio em algum momento de utilização dos aparelhos, mas a entrada, a execução e a saída dos mesmos apresentaram, respectivamente, $75,56 \%, 70,00 \%$ e $93,33 \%$ de pessoas que nunca necessitavam de ajuda humana (figura 6), e $86,67 \%$, $81,11 \%$ e $91,11 \%$ que nunca necessitavam de auxílio de algum objeto (figura 7 ). 
Tabela 2 - Freqüência da pontuação de dificuldade da variável Utilização de Aparelho, Rio de Janeiro, RJ, 2007.

\begin{tabular}{lcc}
\hline \multicolumn{1}{c}{ Aparelho } & Pontuação & Respondentes \\
\hline Supino & 28 & 5 \\
Pulley & 27 & 4 \\
Cross & 16 & 2 \\
Voador & 18 & 3 \\
Leg Press & 44 & 7 \\
C Adutora & 16 & 2 \\
C Abdutora & 13 & 2 \\
C Flexora & 8 & 1 \\
C Extensora & 36 & 5 \\
Mesa Flexora & 20 & 2 \\
Esteira & 57 & 9 \\
Bicicleta & 7 & 2 \\
Outros & 22 & 5 \\
\hline
\end{tabular}

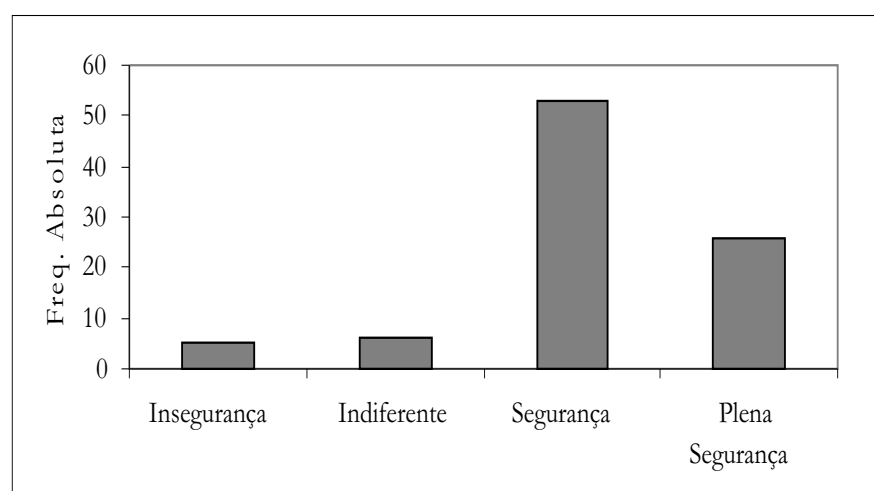

Figura 5 - Freqüência da variável Insegurança, Rio de Janeiro, RJ, 2007.

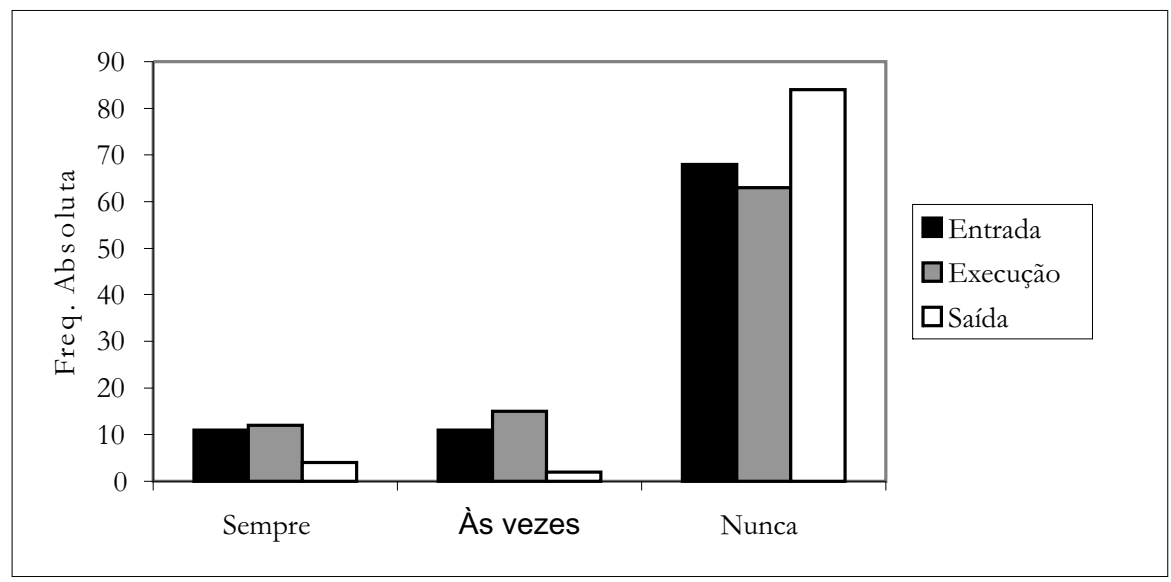

Figura 6 - Freqüência da variável Auxílio Humano, Rio de Janeiro, RJ, 2007. 


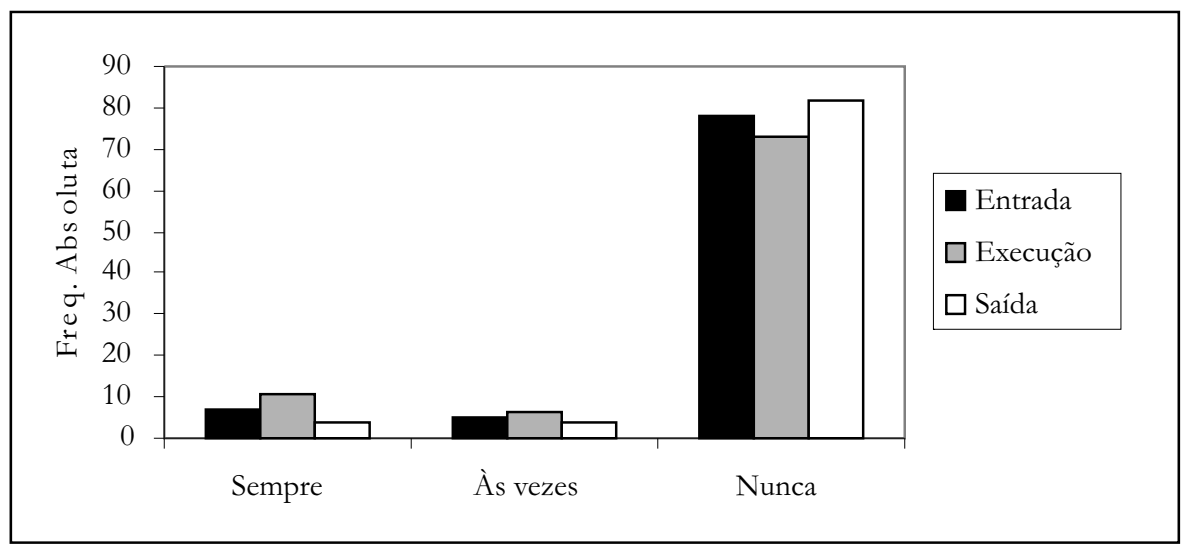

Figura 7 - Freqüência da variável Auxílio Objeto, Rio de Janeiro, RJ, 2007.

O resultado da variável "dificuldade" (tabela 3) apresentou-se dentro da expectativa, tendo em vista que os itens "adaptação" (14,29\%), "insegurança" (14,29\%) e "movimento" (9,52\%), que apresentaram as maiores freqüências, encontram-se interligados, pois falta de adaptação pode gerar insegurança, que por sua vez dificulta os movimentos e tem como agravante o processo de envelhecimento no nível articular e músculo-esquelético. Neves ${ }^{15}$ discutiu que a existência de aspectos como artrose, dores e medo pode contribuir para o aumento da dificuldade de adaptação, elevando o nível de insegurança.

A declaração de alguma dificuldade na realização de exercícios de musculação por somente 21 idosos não guardou correspondência com os resultados da figura 8, a qual demonstrou alto índice de problemas articulares (34,86\% dos problemas), provavelmente em função do desgaste estrutural, perda do líquido sinovial e calcificação da matriz extracelular do tecido cartilaginoso, aspectos inerentes ao processo de envelhecimento. ${ }^{20}$ Sob o título "outros" foram reunidos problemas cardiovasculares, respiratórios e diabetes, o que explica a alta ocorrência.

Cabe ressaltar que, de acordo com o resultado dos itens "muscular" e "ósseo", especialmente no último houve convergência com as expectativas, em função das curvas de desenvolvimento ósseo e muscular. Além disso, houve nestes valores contradição com respostas anteriores, pois os primeiros tiveram por norte a insegurança na utilização dos equipamentos pela perda de massa (muscular e óssea). Todavia, o grupo não possibilitou tal constatação, o que reforça a influência da relação afetiva professor-aluno na coleta subjetiva de dados.

A aplicação do teste Qui-quadrado garantiu que todas as variáveis apresentassem 
Tabela 3 - Freqüência da análise da variável Dificuldade, Rio de Janeiro, RJ, 2007.

\begin{tabular}{lcccc}
\hline \multicolumn{1}{c}{ Classe } & $\begin{array}{c}\text { Freqüência } \\
\text { Absoluta }\end{array}$ & $\begin{array}{c}\text { Freqüência. } \\
\text { Acum. Absoluta }\end{array}$ & $\begin{array}{c}\text { Freqüência } \\
\text { Relativa }\end{array}$ & $\begin{array}{c}\text { Freqüência } \\
\text { Acum. Relativa }\end{array}$ \\
\hline Abaixar & 1 & 1 & 4,76 & 4,76 \\
Acompanhamento & 1 & 2 & 4,76 & 9,52 \\
Adaptação & 3 & 5 & 14,29 & 23,81 \\
Altura & 1 & 6 & 4,76 & 28,57 \\
Artrose & 1 & 7 & 4,76 & 33,33 \\
Atendimento & 1 & 8 & 4,76 & 38,10 \\
Cond. Físco & 1 & 9 & 4,76 & 42,86 \\
Dores & 1 & 10 & 4,76 & 47,62 \\
Execução & 1 & 11 & 4,76 & 52,38 \\
Inestimulante & 1 & 12 & 4,76 & 57,14 \\
Insegurança & 3 & 15 & 14,29 & 71,43 \\
Medo & 1 & 16 & 4,76 & 76,19 \\
Movimento & 2 & 18 & 9,52 & 85,71 \\
Mem. Superiores & 1 & 19 & 4,76 & 90,48 \\
Nomes Técnicos & 1 & 20 & 4,76 & 95,24 \\
Tonteira & 1 & 21 & 4,76 & 100,00 \\
Total & 21 & & 100,00 & \\
\hline
\end{tabular}

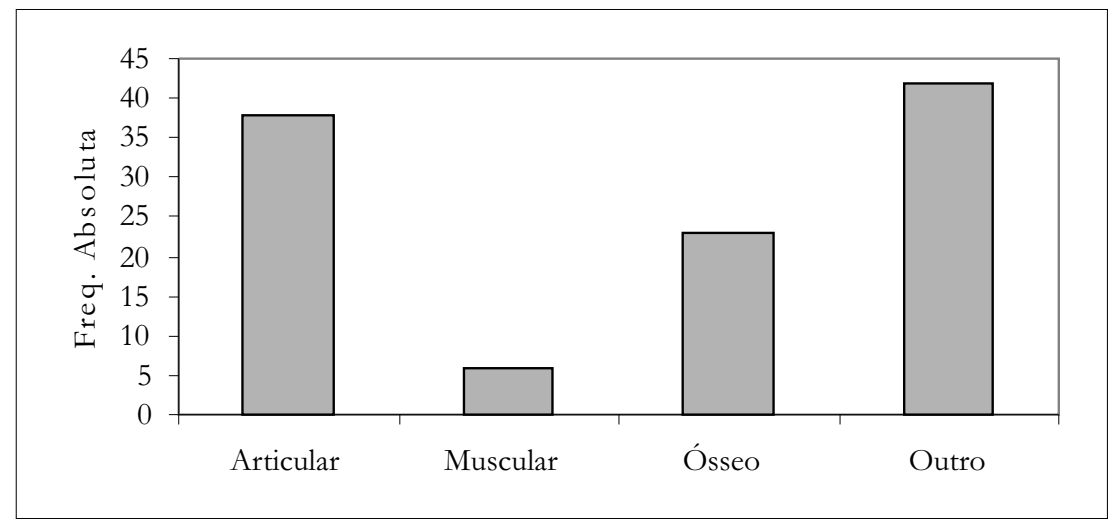

Figura 8 - Frequiência da variável Problema de Saúde, Rio de Janeiro, RJ, 2007. 
freqüências significativas, exceto a dificuldade (tabela 4), ou seja, as diferenças constatadas não ocorreram por acaso e representaram a efetiva opinião do idoso. Com relação aos problemas de saúde, a baixa ocorrência de "muscular" determinou a significância estatística.
A não-significância na variável "dificuldade" ocorreu provavelmente pela associação entre o grande número de opções e as respectivas baixas freqüências absolutas, o que contribui para a diluição e homogeneidade das ocorrências. Todavia, isto não invalida os valores obtidos para cada opção.

Tabela 4 - Resultados do Teste Qui-quadrado, Rio de Janeiro, RJ, 2007.

\begin{tabular}{lcc}
\hline \multicolumn{1}{c}{ Variável } & GL & Valor-p \\
\hline Sexo & 1 & 0,01 \\
Objetivo & 3 & 0,01 \\
Outra Atividade & 7 & 0,03 \\
Insegurança & 3 & 0,02 \\
Auxílio Humano - Entrada & 2 & 0,00 \\
Auxílio Humano - Execução & 2 & 0,00 \\
Auxílio Humano - Saída & 2 & 0,00 \\
Auxílio Objeto - Entrada & 2 & 0,00 \\
Auxílio Objeto - Execução & 2 & 0,00 \\
Auxílio Objeto - Saída & 2 & 0,00 \\
Dificuldade & 15 & 0,42 \\
Problema Saúde & 3 & 0,04 \\
\hline
\end{tabular}

\section{CONCLUSÃO}

O presente estudo objetivou analisar a segurança na utilização de aparelhos de musculação, e para tanto foram investigados 90 indivíduos idosos. Partindo do princípio de que uma grande incidência de problemas articulares e ósseos levaria a uma redução da autonomia funcional, motivada pela pouca flexibilidade, perda natural de força muscular e redução de capacidade de equilíbrio, essa dependência ocasionaria insegurança com relação a aparelhos como esteira, mesa flexora, cadeira extensora, leg press, voador, supino e pulley, principalmente e com relação a movimentos não-naturais, os quais talvez muitos dos idosos nunca tenham realizado. Porém, essa insegurança se apresentou camuflada pela avaliação subjetiva do grupo de idosos a respeito de sua própria percepção de segurança.

Podem-se recomendar, para futuros estudos, modificações no procedimento de coleta de dados, visando a torná-la objetiva. Isso culminaria com o emprego de observações das intervenções disponibilizadas ao público alvo, as quais preferencialmen- 
te deveriam ser filmadas para refinamento das observações e análise do complexo professor-aluno.

No mesmo sentido, um estudo longitudinal com base em avaliações e reavaliações permitiria verificar a correspondência de respostas, percepções e coletas objetivas, acar- retando estimativas epidemiológicas e fidedignidade de dados. Soma-se a isto a necessidade do cruzamento da percepção de segurança com variáveis pertencentes ao domínio psicológico, como auto-estima, independência e depressão, por exemplo; e social, relações pessoais, tamanho do círculo social e necessidade de inclusão, dentre outros.

\section{REFERÊNCIAS}

1. Caldas CP. A saúde do idoso: a arte de cuidar. Rio de Janeiro: EDUERJ; 1998

2. Campos MA. Musculação. Rio de Janeiro: Sprint; 2001.

3. Fleck S, Kraemer WJ. Fundamentos do treinamento de força muscular. Rio de Janeiro: Artmed; 1999.

4. Dantas EHM, Oliveira RJ. Exercício maturidade e qualidade de vida. Rio de Janeiro: SHAPE; 2003

5. Nóbrega ACL, et al. Posicionamento oficial da Sociedade Brasileira de Medicina do Esporte e da Sociedade Brasileira de Geriatria e Gerontologia: Atividade Física e Saúde no Idoso. Revista Brasileira de Medicina do Esporte 1999; 5(6): 207-11.

6. Araújo CGS, Araújo DSMS. Aptidão física, saúde e qualidade de vida relacionada à saúde em adultos. Revista brasileira de medicina esportiva 2000; 6 (5): 194-203

7. Teodoro BG, Moreira PVS, Resende NM, Magalhães AM Espíndola, FS Efeito do treinamento resistido para a terceira idade. Revista Ação e Movimento 2006; 3(3): 27 - 31.

8. N Junior HS, Ramos AT, Lima SB, Cruz KA. Comparação de métodos de validação de formulários em Educação Física. Anais do XXVIII Simpósio Internacional de Ciências do Esporte. São Paulo: Celafiscs; 2005. p. 40.

9. Ramos AT, N Junior HS, Costa AV, Cruz KA. Relação entre percentual de erro e variabilidade de repostas em formulários. Anais do XXVIII Simpósio Internacional de Ciências do Esporte. São Paulo: Celafiscs; 2005. p. 202.

10. Bunchaft G, Kellner SRO Estatística sem mistério. Petrópolis, RJ: Vozes; 1999.

11. Costa Neto PLO. Estatística. São Paulo: Edgard Blücher; 2002.

12. Beiguelman B. Curso prático de bioestatística. Ribeirão Preto: FUNPEC; 2002.

13. Bondim TA. Fatores que motivam pessoas acima de 60 anos a prática de exercícios físicos em academia de ginástica. [monografia]. Rio de Janeiro: Universidade Estácio de Sá; 2004.

14. Lima MP. Gerontologia educacional: uma pedagogia específica para idoso, uma nova concepção de envelhecimento. São Paulo: LTR; 2000.

15. Neves AB. Dança e suas influências na terceira idade. [monografia]. Rio de 
Janeiro: Universidade Estácio de Sá; 2006.

16. Valiño OS, Texeira MF, Vasconcelos FB. Avaliar hábitos de vida de idosos praticantes e não praticantes de atividade física em academias. [monografia]. Rio de Janeiro; Universidade Estácio de Sá; 2007.

17. Nascimento TP. Influência da prática da atividade física sobre a autonomia funcional. [monografia]. Rio de Janeiro: Universidade Estácio de Sá; 2006.
18. Souza L, et al. Qualidade de vida: bemestar dos idosos, um estudo exploratório na população portuguesa. Rev Saude Publica 2003; 37(3): 367-71.

19. Rocas L. Perfil de qualidade de vida de mulheres idosas praticantes de hidroginástica. [monografia]. Rio de Janeiro: Universidade Estácio de Sá; 2003.

20. Junqueira LC, Carneiro J. Histologia básica. Rio de Janeiro: Guanabara Koogan; 1999. 


\section{ANEXO A \\ QUESTIONÁRIO PARA COLETA DE DADOS}

1. Idade: anos

2. Sexo: ( ) Feminino ( ) Masculino

3. Qual o seu Principal Objetivo com a prática da musculação?
( ) Condicionamento Físico
( ) Saúde

( ) Socialização

() Outros:

4. Você faz alguma outra atividade física?
( ) Não
( ) Alongamento
( ) Dança
( ) Ginástica
( ) Hidroginástica
( ) Natação
( ) Yôga
() Outros:

5. Você sente dificuldade na utilização de algum aparelho? Em que grau 1. Mínimo e 10. Máximo:

\begin{tabular}{|l|c|}
\hline \multicolumn{1}{|c|}{ Aparelho } & Grau \\
\hline 1-Supino & \\
\hline 2-Pulley & \\
\hline 3-Cross & \\
\hline 4-Voador & \\
\hline 5-Leg Press & \\
\hline 6-Cadeira Adutora & \\
\hline 7-Cadeira Abdutora & \\
\hline 8-Cadeira Flexora & \\
\hline 9-Cadeira Extensora & \\
\hline 10-Mesa Flexora & \\
\hline 11-Esteira & \\
\hline 12-Bicicleta & \\
\hline 13-Outros & \\
\hline
\end{tabular}


6- Você se sente inseguro(a) quando utiliza algum aparelho?
( ) Plena Insegurança
( ) Insegurança
( ) Indiferente
( ) Segurança
( ) Plena Segurança

7. Caso tenha assinalado a opção Plena Insegurança ou Insegurança, isto se dá em que aparelho(s). Em que grau 1. Mínimo e 10. Máximo:

\begin{tabular}{|l|c|}
\hline \multicolumn{1}{|c|}{ Aparelho } & Grau \\
\hline 1-Supino & \\
\hline 2-Pulley & \\
\hline 3-Cross & \\
\hline 4-Voador & \\
\hline 5-Leg Press & \\
\hline 6-Cadeira Adutora & \\
\hline 7-Cadeira Abdutora & \\
\hline 8-Cadeira Flexora & \\
\hline 9-Cadeira Extensora & \\
\hline 10-Mesa Flexora & \\
\hline 11-Esteira & \\
\hline 12-Bicicleta & \\
\hline
\end{tabular}

8. Desde que iniciou a pratica da musculação você necessita ou necessitou de auxilio humano nos aparelhos?

\begin{tabular}{|l|l|l|l|}
\hline & Sempre & Às vezes & Nunca \\
\hline Entrada & & & \\
\hline Execução & & & \\
\hline Saída & & & \\
\hline
\end{tabular}

9. Desde que iniciou a pratica da musculação você necessita ou necessitou de auxilio de algum objeto?

\begin{tabular}{|l|l|l|l|}
\hline & Sempre & Às vezes & Nunca \\
\hline Entrada & & & \\
\hline Execução & & & \\
\hline Saída & & & \\
\hline
\end{tabular}


10. Você já sofreu algum tipo de queda em algum aparelho? Qual?

\begin{tabular}{|l|l|l|l|}
\hline \multicolumn{1}{|c|}{ Aparelho } & Entrada & Execução & Saída \\
\hline 1-Supino & & & \\
\hline 2-Pulley & & & \\
\hline 3-Cross & & & \\
\hline 4-Voador & & & \\
\hline 5-Leg Press & & & \\
\hline 6-Cadeira Adutora & & & \\
\hline 7-Cadeira Abdutora & & & \\
\hline 8-Cadeira Flexora & & & \\
\hline 9-Cadeira Extensora & & & \\
\hline 10-Mesa Flexora & & & \\
\hline 11-Esteira & & & \\
\hline 12-Bicicleta & & \\
\hline
\end{tabular}

11.Você já sofreu algum tipo de acidente, exceto queda, em algum aparelho? Qual?

\begin{tabular}{|c|c|c|c|}
\hline Aparelho & Entrada & Execução & Saída \\
\hline \multicolumn{4}{|l|}{ 1-Supino } \\
\hline \multicolumn{4}{|l|}{ 2-Pulley } \\
\hline \multicolumn{4}{|l|}{ 3-Cross } \\
\hline \multicolumn{4}{|l|}{ 4-Voador } \\
\hline \multicolumn{4}{|l|}{ 5-Leg Press } \\
\hline \multicolumn{4}{|l|}{ 6-Cadeira Adutora } \\
\hline \multicolumn{4}{|l|}{ 7-Cadeira Abdutora } \\
\hline \multicolumn{4}{|l|}{ 8-Cadeira Flexora } \\
\hline \multicolumn{4}{|l|}{ 9-Cadeira Extensora } \\
\hline \multicolumn{4}{|l|}{ 10-Mesa Flexora } \\
\hline \multicolumn{4}{|l|}{ 11-Esteira } \\
\hline 12-Bicicleta & & & \\
\hline
\end{tabular}


12- Qual a maior dificuldade encontrada por você na pratica da musculação? Por quê?

13- Possui algum tipo de problema de saúde?
( ) Articular
( ) Muscular
( ) Ósseo
( ) Outro: Curso de Educação Física 